\title{
Prevalence of Postpartum Depression in a Tertiary Health Care
}

\author{
Priza Pradhananga, ${ }^{1}$ Prajita Mali, ${ }^{1}$ Lisasha Poudel, ${ }^{1}$ Minani Gurung ${ }^{2}$ \\ 'Department of Public Health, Om Health Campus, Kathmandu, Nepal, ${ }^{2}$ Nepal Institute of Development Studies, Kathmandu, \\ Nepal.
}

\section{ABSTRACT}

Introduction: Postpartum Depression is an important public health problem in developing country like Nepal.Although prevalence of postpartum depression is high in our setting, it is most neglected area of mental health. These have negative consequences not only to mother but also to infant. Data related to postpartum depression in Nepal are limited, research in this particular field will contribute in knowing the gravity of the situation and helps to formulate the factor association to upcoming researchers. This research is done in order to find out the prevalence of postpartum depression.

Methods: A descriptive cross-sectional study was carried out in Paropakar Maternity and Women's Hospital, among total 348 postnatal mothers who were selected through convenient sampling technique. Validated Nepalese version of Edinburg Postnatal Depression Scale was used to screen depressive symptoms. Data was collected after receiving ethical approval letter. Data entry was done using SPSS version 20.

Results: Out of total mothers, the prevalence of Postpartum Depression (PPD) was seen among 51 $(14.7 \%)$ mothers.

Conclusions: Postpartum Depression being a common yet neglected area of maternal health in Nepal, should be detected in early stage. As the study showed that about one sixth of mothers had postpartum depression, more focus should be given to maternal mental health.

Keywords: postpartum depression; prevalence; tertiary health care.

\section{INTRODUCTION}

Postpartum Depression is one of the mental health problems that is a complex mix of physical, emotional, as well as behavioral changes occurring in women after giving birth. It can occur within 4 weeks after delivery, or even 3-12 months. According to the Diagnostic and Statistical Manual of Mental Disorders, fourth edition (DSM-IV), an episode of depression is considered to have postpartum onset if it begins within four weeks after delivery. ${ }^{1}$

Maternity care is still poor in Nepal. Just over onethird of women nation-wide have access to skilled birth attendants. ${ }^{2}$ Postpartum depression (PPD) is a neglected area of maternal health care in developing countries like Nepal. However, it is important to identify and treat postpartum depression because it can have grave consequences for both the mother and her children. ${ }^{3}$

The main aim of this study was to determine the prevalence of postpartum depression among postpartum mothers attending a child immunization clinic at a maternity hospital in Kathmandu, Nepal.

\section{METHODS}

This descriptive cross-sectional was conducted in Paropakar Maternity and Women's Hospital, Kathmandu. The study population was mothers with 6 to 10 weeks postpartum, who attended an immunization clinic. Data

Correspondence: Lisasha Poudel, Om Health Campus, Kathmandu, Nepal. Email: Lisashapoudel01@gmail.com, Phone: +977. 9843540915 . 
collection period was one month from June 2019 to July 2019.

The ethical approval of the study was obtained from the Institutional Review Board of Paropakar Maternity and Women's Hospital (PMWH), Thapathali (Ref No. 59-11-2171). Letter of approval was taken from Paropakar Maternity and Women's Hospital (PMWH) for data collection. Written informed consent from the participants was taken before starting the interview.

The inclusion criteria of the study were mothers at 6-10 weeks of postpartum period who did not have any psychiatric problem, attending immunization clinic who provided consent to be a part of this research. Similarly, women who were not well due to perinatal medical complications, who had pre-existing chronic physical and mental illness were excluded. The sample of 348 mothers were selected by using convenient sampling.

Prevalence i.e. $29 \%$ was taken from a study conducted in Nepal. ${ }^{3}$ Sample size was calculated by using the formula given below:

Sample size $(n)=Z^{2} X p X q / e^{2}$

$$
\begin{aligned}
& =(1.96)^{2} \times 0.29 \times 0.71 /(0.05)^{2} \\
& =0.7909 / 0.0025 \\
& =316
\end{aligned}
$$

Where

$\mathrm{n}=$ sample size

$\mathrm{p}=$ prevalence $=29 \%=0.29$

$q=1-p=1-0.29=0.71$

$\mathrm{e}=$ margin of error $=5 \%=0.5$

$Z=1.96$ at $95 \%$ confidence interval

Hence, taking non-response rate of $10 \%$, the sample size for the study was calculated and found to be 348 . The tool used for data collection in the study was Semi structured questionnaire with Validated Nepalese version Edinburg Postnatal Depression Scale. Edinburg Postnatal Depression Scale was used to calculate prevalence of Postpartum Depression with cut-off value of $\geq 12$ which screened for depressive symptoms. Semi structured questionnaire consisted of Sociodemographic profile. Statistical analysis was done with SPSS 23 version.

\section{RESULTS}

Among 348 respondents, the prevalence of postpartum depression was $51(14.7 \%$ ) (EPDS score >12) (Table 1).

\begin{tabular}{|ll|}
\hline $\begin{array}{l}\text { Table 1. Prevalence of Postpartum Depression } \\
\text { ( } \mathbf{n}=\mathbf{3 4 8}) .\end{array}$ \\
\hline $\begin{array}{l}\text { Postpartum Mothers with Depres- } \\
\text { sive Symptoms (EPDS }>12)\end{array}$ \\
Yes & $51(14.7)$ \\
No & $297(85.3)$ \\
\hline
\end{tabular}

Among 348 respondents interviewed, the mean age was 26 (SD: 4.96) and almost half of them 176 (50.6\%) were 16-25 years of age. The majority of mothers were Hindus 266 (76.4\%), housewives 294 (84.5\%) belonging to non-Dalit ethnicity 317 (91.1\%) and literate $294(84.5 \%)$. Almost 298 (85\%) of households had an average family income of less than 50,000 Nepalese Rupees per month. All of the respondents were married in which about 199 (57.2\%) had a love marriage and most of them $216(62.1 \%)$ were from nuclear families. Majority of the respondents gave birth to the male child 183 (52.6\%) (Table 2).

\begin{tabular}{|c|c|}
\hline Variables & n (\%) \\
\hline \multicolumn{2}{|l|}{ Age } \\
\hline $16-25$ & $176(50.6)$ \\
\hline $26-35$ & $161(46.3)$ \\
\hline $36-45$ & $11(2.9)$ \\
\hline \multicolumn{2}{|l|}{ Religion } \\
\hline Hindu & $266(76.4)$ \\
\hline Non-Hindu & $82(23.6)$ \\
\hline \multicolumn{2}{|l|}{ Ethnicity } \\
\hline Dalit & 31 (8.9) \\
\hline Non-Dalit & $317(91.1)$ \\
\hline \multicolumn{2}{|c|}{ Educational status } \\
\hline Illiterate & $54(15.5)$ \\
\hline Literate & $294(84.5)$ \\
\hline \multicolumn{2}{|l|}{ Occupation } \\
\hline Employed & $54(15.5)$ \\
\hline Housewife & $294(84.5)$ \\
\hline \multicolumn{2}{|c|}{ Marital Status } \\
\hline Married & $348(100)$ \\
\hline \multicolumn{2}{|c|}{ Monthlyincome(NRs) } \\
\hline$<50000$ & $298(85.6)$ \\
\hline$>50000$ & $50(14.4)$ \\
\hline \multicolumn{2}{|l|}{ Family type } \\
\hline Joint & 132 (37.9) \\
\hline
\end{tabular}

Table 2. Socio-demographic factors of postpartum mothers $(n=348)$. 


\begin{tabular}{|lc|} 
Nuclear & $216(62.1)$ \\
Larriage type & \\
Arranged marriage & $199(57.2)$ \\
Sex of baby & $149(42.8)$ \\
Male & \\
Female & $183(52.6)$ \\
\hline
\end{tabular}

Among the subgroup, almost $40 \%$ of mothers $36-45$ years of age had depressive symptoms. Depression among mothers who were literate, non-Hindu and Dalit were $15.3 \%, 17.1 \%$ and $25.8 \%$ respectively. Likewise, $16.4 \%$ of the mothers whose households had an average family income of less than 50,000 Nepalese Rupees per month and belonged to joint family (13\%) were more likely to develop depressive symptoms. $17.6 \%$ of the mothers who had love marriage and gave birth to a female child (15.2\%) developed depressive symptoms.

\section{DISCUSSION}

The prevalence of Postpartum Depression in this study was found to be $14.7 \%$ which was much lower than the level reported in the previous study conducted in Nepal; that reported the prevalence of $29 \% .^{3}$ Also, a recent study conducted in $\mathrm{PMWH}$ showed the prevalence slightly higher; $17.1 \%$ than this study. ${ }^{4}$

The prevalence of PPD amongst Nepalese women assessed by the EPDS screening test $(14.7 \%)$ was comparatively lower to the results obtained using this test in many other developed countries, including Norway $10.1 \%{ }^{5}$ Sweden $12.5 \%,{ }^{6}$ and Canada $8.46 \%{ }^{7}$ However, it is higher in developing countries like India 22\%,8 Pakistan 28.8\%,9 Indonesia 22.35\%, ${ }^{10}$ Argentina $18.6 \%,{ }^{11}$ Bangladesh $22 \% .{ }^{12}$ The results clarified that PPD was most common in developing countries and especially high in Asian countries. This might be because women in developed countries have access to different quality health services like family planning, reproductive health programs, ANC and PNC services, safe delivery services, promotion of maternal nutrition, infant care and so on.

Another study conducted in Nepal showed a prevalence of PPD $30 \%$ which was much higher than this study. This might be due to a higher cut off point of EPDS score $(>12)$ compared to the previous study. ${ }^{13}$ Findings were consistent with that of Kunwar D who reported that depression was most common among postpartum mothers who were housewives, belonged to Dalit ethnicity. ${ }^{3}$

In the present study, postpartum depression was more in older women (36-45 years) which might be because older women might have difficulty to cope up with the outcomes of pregnancy as compared to mothers of younger age. Employed postpartum mothers might have an extra burden of work as compared to housewives which might be a factor to cause depression after childbirth.

Our study has some limitations. Firstly, the EPDS used is only a symptomatic assessment of depression and is not a clinical diagnosis. Also, the immunization clinic was selected as our setting for data collection so, findings cannot be generalized in a community setting.

\section{CONCLUSIONS}

Postpartum Depression a common yet neglected area of maternal health in Nepal. If detected in early stage, help can be provided and many unnecessary inconveniences could be avoided. This study shows that about one sixth of mothers had postpartum depression. Maternal mental health should also be given equal priority. It can be reliably detected by using the EPDS screening test. These results may have implications for the planning of mental health resources for women in other developing countries. Policies can be formulated to encourage postpartum women to obtain adequate rest during pregnancy, support women with poor partner relationship, reduce marital dissatisfaction, help women adjust with stressful life events, and prevent and manage abortion appropriately. These policies may reduce harmful consequences of postpartum depressive symptoms for women, newborn and their family.

\section{ACKNOWLEDGEMENTS}

We would like to acknowledge Dr. Bibek Rajbhandari and Associate Professor Susmita Nepal for their help during the study.

\section{Conflict of Interest: None.}




\section{REFERENCES}

1. Stewart DE, Vigod S. Postpartum depression. N Engl J Med. 2016;375(22):2177-86. [라Med | Full Text | DOI]

2. Van Teijlingen E, Simkhada P, Devkota B, Fanning P, Ireland J, Simkhada B, et al. Mental health issues in pregnant women in Nepal. Nepal J Epidemiol. 2015;5(3):499. [PubMed | DOI]

3. Kunwar D, Corey EK, Sharma P, Risal A. Screening for Postpartum Depression and Associated Factors among Women who Deliver at a University Hospital, Nepal. Kathmandu Univ Med J (KUMJ). 2015 Jan-Mar;13(49):44-8. [PubMed | Full Text | DOI]

4. Bhusal BR, Bhandari N. Identifying the factors associated with depressive symptoms among postpartum mothers in Kathmandu, Nepal. Int J Nurs Sci. 2018;5(3):268-74. [PubMed | Full Text | DOI]

5. Glavin K, Smith L, Sørum R. Prevalence of postpartum depression in two municipalities in Norway. Scand J Caring Sci. 2009 Dec;23(4):705-10. [uuMed | Full Text | DOI]

6. Wickberg B, Hwang CP. Screening for postnatal depression in a population-based Swedish sample. Acta Psychiatr Scand. 1997 Jan;95(1):62-6. [PubMed | Full Text | DOI]

7. Lanes A, Kuk JL, Tamim H. Prevalence and characteristics of postpartum depression symptomatology among Canadian women: a cross-sectional study. BMC Public Health. 2011 May 11;11:302. [마bMed | Full Text | DOI]
8. Upadhyay RP, Chowdhury R, Salehi A, Sarkar K, Singh SK, Sinha B, et al. Postpartum depression in India: a systematic review and meta-analysis. Bull World Health Organ. 2017 Oct 1;95(10):706-17C. [PubMed | Full Text | DOI]

9. Ali NS, Ali BS, Azam IS. Post partum anxiety and depression in peri-urban communities of Karachi, Pakistan: a quasi-experimental study. BMC Public Health. 2009 Oct 12;9:384. [PubMed | Full Text | DOI]

10. Edwards GD, Shinfuku N, Gittelman M, Ghozali EW, Haniman F, Wibisono S, et al. Postnatal depression in Surabaya, Indonesia. Int J Ment Health. 2006;35(1):62-74. [Full Text]

11. Mathisen SE, Glavin K, Lien L, Lagerløv P. Prevalence and risk factors for postpartum depressive symptoms in Argentina: a cross-sectional study. Int J Womens Health. 2013 Nov 21;5:787-93. [라Med | Full Text | DOI]

12. Gausia K, Fisher C, Ali M, Oosthuizen J. Magnitude and contributory factors of postnatal depression: a community-based cohort study from a rural subdistrict of Bangladesh. Psychol Med. 2009 Jun;39(6):999-1007. [PubMed | Full Text | DOI]

13. Giri RK, Khatri RB, Mishra SR, Khanal V, Sharma VD, Gartoula RP. Prevalence and factors associated with depressive symptoms among post-partum mothers in Nepal. BMC Res Notes. 2015 Mar 31;8(1):111. [PubMed |

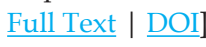

This work is licensed under a Creative Commons Attribution 4.0 International License. The images or other third party material in this article are included in the article's Creative Commons license, unless indicated otherwise in the credit line; if the material is not included under the Creative Commons license, users will need to obtain permission from the license holder to reproduce the material. To view a copy of this license, visit http://creativecommons.org/licenses/by/4.0/ 